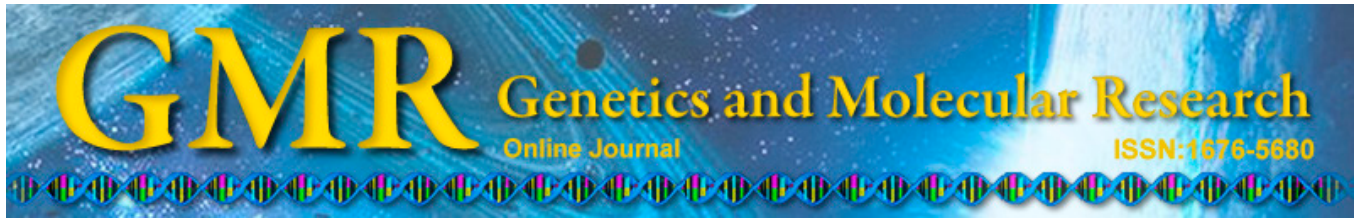

\title{
Molecular characterization of the endophytic fungal community associated with Eichhornia azurea (Kunth) and Eichhornia crassipes (Mart.) (Pontederiaceae) native to the Upper Paraná River floodplain, Brazil
}

\author{
T.T. Almeida ${ }^{1}$, R.C. Orlandelli ${ }^{1}$, J.L. Azevedo ${ }^{2}$ and J.A. Pamphile ${ }^{1}$ \\ ${ }^{1}$ Departamento de Biotecnologia, Genética e Biologia Celular (DBC), \\ Universidade Estadual de Maringá, Maringá, PR, Brasil \\ 2Departamento de Genética, Escola Superior de Agricultura "Luiz de Queiroz", \\ USP, Piracicaba, SP, Brasil \\ Corresponding author: J.A. Pamphile \\ E-mail: prof.pamphile@gmail.com / japamphile@uem.br
}

Genet. Mol. Res. 14 (2): 4920-4931 (2015)

Received July 24, 2014

Accepted December 11, 2014

Published May 11, 2015

DOI http://dx.doi.org/10.4238/2015.May.11.25

\begin{abstract}
Endophytic fungi live in the interior of healthy plants without causing them any damage. These fungi are of biotechnological interest; they may be used in the biological control of pests and plant diseases, and in the pharmaceutical industry. The aquatic macrophytes Eichhornia azurea (Kunth) and Eichhornia crassipes (Mart.) belong to the Pontederiaceae family. The first is a fixed-floating species and the second is a free-floating species that is known for its phytoremediation potential. The fungal endophytes associated with the leaves of $E$. azurea and E. crassipes, native to the Upper Paraná River floodplain, Brazil, were isolated. The sequencing of the ITS1-5.8S-ITS2 region of ribosomal DNA was performed and the nucleotide sequences obtained were compared with those available in the GenBank database for the
\end{abstract}


molecular identification of the isolates. The construction of phylogenetic trees was performed using the MEGA5 software. The results showed that high colonization frequencies were obtained from the 610 foliar fragments sampled from each plant: $87.86 \%$ for E. azurea and $88.85 \%$ for $E$. crassipes. At the genus level, it was possible to identify 19 fungal endophytes belonging to the genera Alternaria, Bipolaris, Cercospora, Diaporthe, Gibberella, Pestalotiopsis, Plectosphaerella, Phoma, and Saccharicola. Two other endophytes were identified at the species level (Microsphaeropsis arundinis). Genera Bipolaris, Cercospora, Microsphaeropsis, and Phoma were found as endophytes in the two macrophytes and the other genera were host-specific, being isolated from only one macrophyte, proving that there is a small difference in the endophytic diversity of the two Eichhornia species analyzed.

Key words: Aquatic macrophytes; Endophytes; Molecular identification; Phylogeny

\section{INTRODUCTION}

Aquatic macrophytes, along with phytoplankton, are considered the principal biological indicators of pollution (Esteves, 1998). They play an important role in nutrient processing and water flow regulation, and they absorb toxic substances (Marques, 1999). However, owing to their excessive growth in some countries, such as South Africa, these plants are considered aquatic weeds that have caused damage to several sectors of human development (Azevedo Netto, 1988; Cilliers, 1998).

Eichhornia azurea (Kunth), from the Pontederiaceae family, is a fixed-floating species of macrophyte (Thomaz and Bini, 2003), commonly known in Brazil as "aguapé de baraço", which is abundant in wetlands and is easily identified by its long rhizomes. This plant is used as a substrate by many insects and other invertebrates (Lima et al., 2003; Souza-Franco et al., 2009), and it has also been used to decompose organic matter in tropical reservoirs (da CunhaSantino, 2010).

Another aquatic macrophyte from the same genus, Eichhornia crassipes (Mart.), commonly known in Brazil as "aguapé", "gigoga", "rainha-dos-lagos", or "jacinto-d'água", is a free-floating species. It has wide ecological significance owing to its properties as a bio-filter, its ability to accumulate heavy metals (Chigbo et al., 1982; Casabianca, 1985), and its potential for the production of metabolites of biotechnological interest (Aboul-Enein et al., 2011).

Some microorganisms, mainly fungi and bacteria, inhabit the interior of plant tissues and organs without causing any damage to their hosts. They are known as endophytes or endophytic microorganisms. An endophyte can occupy the host plant throughout the endophyte's entire lifecycle or for just one phase of its development, occurring especially in the aerial parts of the host without producing nodules or other external transformations. On the contrary, plant-endophyte interactions promote some advantages to the host, such as modification of plant physiology and protection against insect pests and phytopathogenic microorganisms. Furthermore, the production of substances of biotechnological interest, such as enzymes, antibiotics, alkaloids, and other compounds, by endophytes has been reported (Azevedo et al., 2002; Peixoto Neto et al., 2002). 
Endophytic fungi have a variety of applications and have attracted the attention of the scientific community (Souza et al., 2004), and molecular methods have been employed to extend our knowledge of endophytic diversity and taxonomy (Linnakoski et al., 2012). Analysis of ribosomal DNA (rDNA) is commonly used to estimate the diversity of fungal endophytes (García et al., 2012), where the amplification of the internal transcribed spacer region (ITS1-5.8S-ITS2) rDNA by the polymerase chain reaction (PCR), described by Mullis and Faloona in 1987, is combined with procedures of amplicon sequencing and similarity analyses between the sequences obtained in studies and those deposited in databases such as GenBank (Orlandelli et al., 2012; Rhoden et al., 2012).

Considering the shortage of information about endophytes from aquatic macrophytes, the aim of this study was the isolation and molecular characterization of endophytic fungi inhabiting E. azurea and E. crassipes to determine endophytic diversity. We sequenced the ITS1-5.8S-ITS2 region of rDNA and performed a phylogenetic analysis by comparing the obtained sequences with others deposited in GenBank, using the Basic Local Alignment Search Tool (BLAST).

\section{MATERIAL AND METHODS}

\section{Isolation of endophytic fungi}

Mature, symptomless and undamaged leaves of E. azurea and E. crassipes were randomly collected from the Upper Paraná River floodplain, UEM/Base Avançada do Nupélia, municipality of Porto Rico, Paraná, Brazil $\left(22^{\circ} 48^{\prime} \mathrm{S}, 53^{\circ} 12^{\prime} \mathrm{W}\right)$. A surface disinfection of leaves with sodium hypochlorite solution, according to Araújo et al. (2010), was performed to ensure that only endophytes, and not epiphytes, were obtained in the isolation process. After disinfection, a fragmentation technique was used for the isolation of endophytic fungi, where foliar fragments (approximately $3 \mathrm{~mm}^{2}$ ) were distributed on Petri dishes containing potato dextrose agar culture medium supplemented with tetracycline $(50 \mu \mathrm{g} / \mathrm{mL}$ in $50 \%$ ethanol) to prevent bacterial growth. Dishes were incubated at $28^{\circ} \mathrm{C}$ in conditions of biochemical oxygen demand for 7 days.

\section{Molecular identification of endophytic isolates}

Genomic DNA was extracted following the methodology described by Pamphile and Azevedo (2002), except that endophytes had previously been grown for 7 days at $28^{\circ} \mathrm{C}$, on Petri dishes with potato dextrose broth. The DNA concentration and integrity were checked by electrophoresis on 1\% agarose gel using a High DNA Mass Ladder (Invitrogen, California, USA) as the DNA molecular weight standard. After electrophoresis, the agarose gel was photo-documented. The final concentration of DNA was adjusted to $10 \mathrm{ng} / \mathrm{mL}$.

PCR amplification of the ITS1-5.8S-ITS2 region of rDNA was performed using primer ITS1 (5'-TCCGTAGGTGAACCTGCGG-3'), as described by Rhoden et al. (2012), and primer ITS4 (5'-TCCCCGCTTATTGATATGC-3'), as described by White et al. (1990). Following PCR, products were purified with GFX PCR DNA and Gel Band Purification kits (Amersham Biosciences) in accordance with manufacturer instructions. Afterwards, samples were quantified again by electrophoresis on $1 \%$ agarose gel, and photo-documented. 
The samples were prepared for sequencing by PCR. For the final volume of $10 \mu \mathrm{L}$, $4 \mu \mathrm{L}$ sequencing solution, $1 \mu \mathrm{L}$ primer ITS1, $2 \mu \mathrm{L}$ previously purified DNA samples, and 3 $\mu \mathrm{L}$ Milli-Q water were used. The reaction mixture was placed in a TTC-100 thermocycler (MJ Research, Inc.) programmed to conduct 35 cycles after an initial denaturation of 2 min at $95^{\circ} \mathrm{C}$. Each amplification cycle consisted of three steps: denaturation $\left(95^{\circ} \mathrm{C}, 1 \mathrm{~min}\right)$, annealing $\left(55^{\circ} \mathrm{C}, 1 \mathrm{~min}\right)$, and elongation $\left(60^{\circ} \mathrm{C}, 1 \mathrm{~min}\right)$. The final elongation was at $60^{\circ} \mathrm{C}$ for $5 \mathrm{~min}$.

Samples were sequenced in a MegaBACE ${ }^{\mathrm{TM}} 1000$ automated sequencer (Amersham Biosciences) with $1 \mathrm{kV} / 90 \mathrm{~s}$ and $7 \mathrm{kV} / 240 \mathrm{~min}$ as injection and electrophoresis conditions, respectively. Obtained sequences were analyzed and edited. For the identification of endophytic fungi, percentages of sequence identity and coverage were compared with available sequences in GenBank (http://www.ncbi.nlm.nih.gov) using BLASTn to search for the closest matched sequences. The sequence data from this study were submitted to GenBank under accession Nos. KF852579 to KF852601.

\section{Determination of genetic distance of isolates}

The obtained sequences were aligned using version 5.0 of the MEGA program (Tamura et al., 2011) with grouping by neighbor-joining method (Saitou and Nei, 1987), using the p-distance matrix for nucleotides with the pairwise gap deletion option and with 10,000 bootstrap (BP) repetitions. After analysis of consensus sequences, a global alignment was made with the sequences obtained in this study and the closest matched sequences available in GenBank.

Sequences were aligned using ClustalW (Thompson et al., 1994) and the dendrogram was made with version 5.0 of the MEGA program. The evolutionary distance was calculated by the Jukes \& Cantor method (Saitou and Nei, 1987). A numerical matrix was generated, where each value represented the estimation of the distance between each pair of sequences. To avoid an underestimation of the real evolutionary distance between the organisms, the program applies a specific evolutionary model, with correction for the occurrence of multiple substitutions.

After the distance matrix, the topology of the phylogenetic tree was reconstructed using the neighbor-joining method. This method starts from a topology without resolution (star) and then searches, in each cycle, the pair of sequences which contributes the smallest sum of branches to the tree topology (minimum evolution method) (Rhoden et. al., 2013).

\section{RESULTS}

\section{Isolation and molecular identification of endophytic fungi from E. azurea and E. crassipes}

From the total of 610 leaf fragments sampled from each aquatic macrophyte, similar colonization frequencies were obtained for E. azurea (87.86\%) and E. crassipes $(88.85 \%)$. The absence of microbial growth in both negative controls proved the efficiency of the surface-disinfection process.

From the endophytes isolated from E. azurea, 20 were randomly selected and grouped into eight morphogroups, according to their morphological characteristics, such as colony coloration, pigment formation, development, and growth of mycelial colonies on potato dextrose agar. Seventeen isolates from E. crassipes were randomly selected and grouped into 13 morphogroups. 
By using data from the sequencing analysis of the ITS1-5.8S-ITS2 region of rDNA and through BLAST analysis (http://www.ncbi.nlm.nih.gov/blast/) of the GenBank database, it was possible to identify 21 fungal isolates from the total of 37 endophytes studied, being 13 isolates from E. azurea and 8 isolates from E. crassipes (Table 1).

Table 1. Isolated and identified endophytes from each host plant, relationship with the genus or species, and the identity percentage found in the NCBI (National Center for Biotechnology Information) website.

\begin{tabular}{|c|c|c|c|}
\hline Endophytes & Host plants & Closely related fungal sequences & Identity $(\%)$ \\
\hline $\mathrm{C} 4$ & E. crassipes & Bipolaris sp GU017499.1 & 99 \\
\hline $\mathrm{C} 5$ & E. crassipes & Microsphaeropsis arundinis JX077029.1 & 99 \\
\hline C6 & E. crassipes & Curvularia trifolii KC415610.1 & 99 \\
\hline $\mathrm{C} 8$ & E. crassipes & Bipolaris papendorfii JQ753972.1 & 99 \\
\hline C9 & E. crassipes & Cercospora kikuchii AY633838.1 & 99 \\
\hline $\mathrm{C} 21$ & E. crassipes & Plectosphaerella cucumerina DQ779781.1 & 99 \\
\hline $\mathrm{C} 25$ & E. crassipes & Phoma sp KC662225.1 & 87 \\
\hline $\mathrm{C} 26$ & E. crassipes & Bipolaris sorokiniana JQ753977.1 & 99 \\
\hline $\mathrm{AZ2}$ & E. azurea & Gibberella moniliformis AB649145.1 & 99 \\
\hline AZ5 & E. azurea & Diaporthe sp KC981086.1 & 93 \\
\hline $\mathrm{AZ7}$ & E. azurea & Saccharicola bicolor AF455415.1 & 96 \\
\hline AZ11 & E. azurea & Saccharicola bicolor AF455415.1 & 95 \\
\hline AZ12 & E. azurea & Cercospora sp HQ232415.1 & 99 \\
\hline AZ13 & E. azurea & Alternaria palandui FJ418180.1 & 99 \\
\hline AZ16 & E. azurea & Alternaria alternata JN618076.1 & 99 \\
\hline AZ19 & E. azurea & Alternaria gaisen KF293768.1 & 99 \\
\hline AZ20 & E. azurea & Phoma sp KC005684.1 & 97 \\
\hline AZ26 & E. azurea & Bipolaris papendorfii JQ753972.1 & 90 \\
\hline AZ36 & E. azurea & Pestalotiopsis sp JX436803.1 & 97 \\
\hline AZ37 & E. azurea & Microsphaeropsis arundinis JX077029.1 & 100 \\
\hline AZ38 & E. azurea & Alternaria mali JF802106.1 & 99 \\
\hline
\end{tabular}

\section{Phylogenetic analysis of $E$. azurea endophytes based on data from rDNA sequencing}

Phylogenetic analysis separated the fungal endophytes from E. azurea in nine clades composed only of representatives from the phylum Ascomycota (Figure 1).

The first clade comprises fungi from the class Dothideomycetes and the order Pleosporales, with representatives from the genus Alternaria. The isolate AZ16 (99\% identity with Alternaria alternata JN618076.1 by BLAST) was grouped to Alternaria sp with $12 \%$ BP. The isolate AZ13 (99\% identity with Alternaria palandui FJ418180.1 by BLAST) was grouped to Alternaria palandui with $58 \%$ BP. In this case, species classification was confirmed. The endophytes AZ19 (99\% identity with Alternaria gaisen KF293768.1 by BLAST) and AZ38 (99\% identity with Alternaria mali JF802106.1 by BLAST) were grouped to other Alternaria fungi from this clade with $100 \% \mathrm{BP}$, confirming the classification at the genus level.

The second clade is formed of fungi from the class Dothideomycetes and the order Pleosporales, with representatives from the genus Bipolaris. The endophyte AZ26 (90\% identity with Bipolaris papendorfii JQ753972.1 by BLAST) was grouped to Bipolaris sp (JX406577.1) with 57\% BP, confirming its genus identification.

The third clade comprises fungi from the class Dothideomycetes and the order Pleosporales, with isolates from the genus Phoma. The isolate AZ20 (97\% identity with Pho$m a$ sp KC005684.1 by BLAST) was grouped to Phoma isolates (KC005684.1, KC005682.1, GU045305.1, and FJ950743.1) with 100\% BP, identified at the genus level. 


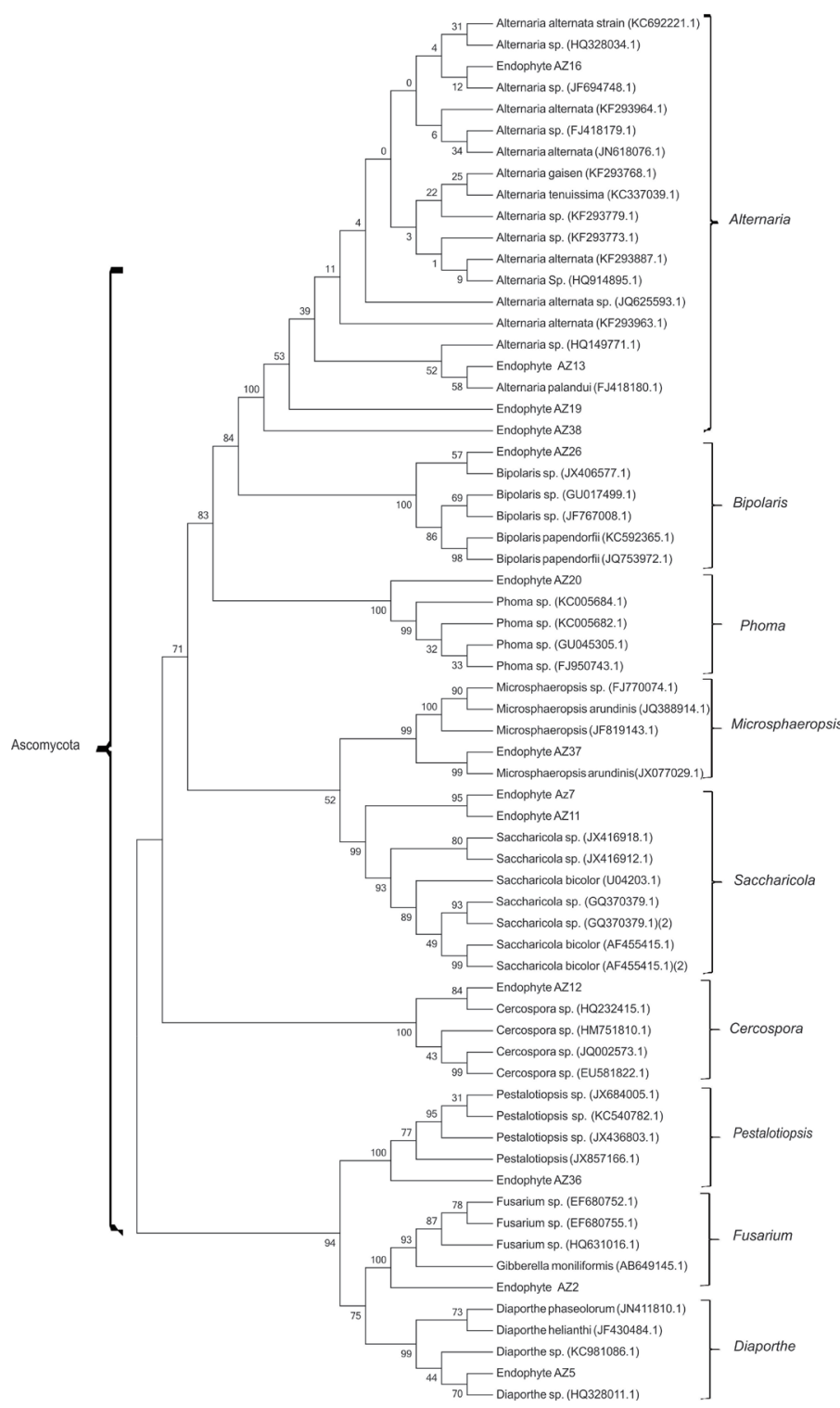

Figure 1. Phylogenetic tree constructed with endophytic sequences from Eichhornia azurea and sequences from GenBank (indicated by database code), using the neighbor-joining method and the p-distance matrix for nucleotides, with the pairwise gap deletion option. The numbers above and beneath each knot indicate the frequency (\%) of each branch in bootstrap analyses of 10,000 repetitions. All clades comprise fungi from the phylum Ascomycota. Clades I to V comprise fungi from the class Dothideomycetes and the order Pleosporales, with genera Alternaria (clade I), Bipolaris (clade II), Phoma (clade III), Microsphaeropsis (clade IV), and Saccharicola (clade V). Clade VI comprises fungi from the class Dothideomycetes, the order Capnodiales, and the genus Cercospora. Clade VII comprises fungi from the class Sordariomycetes, the order Xylariales, and the genus Pestalotiopsis. Clade VIII comprises fungi from the class Sordariomycetes, the order Hypocreales, and the genera Fusarium and Gibberella. Clade IX comprises fungi from the class Sordariomycetes, the order Diaporthales, and the genus Diaporthe. 
The fourth clade comprises Microsphaeropsis fungi from the class Dothideomycetes and the order Pleosporales. The endophyte AZ37 (100\% identity with Microsphaeropsis arundinis JX077029.1 by BLAST) was grouped to the same isolate, with $99 \%$ BP, since this isolate had the closest similarity by BLAST. Therefore, species identification based on rDNA sequencing was confirmed.

The fifth clade comprises fungal representatives from the class Dothideomycetes, the order Pleosporales, and the genus Saccharicola, where the endophytic isolates AZ7 and AZ11 (96 and 95\% identity, respectively, with Saccharicola bicolor AF455415.1 by BLAST) were grouped to the Saccharicola genus with $95 \%$ BP, confirming their identification at the genus level.

The sixth clade is formed by fungal isolates from the class Dothideomycetes, the order Capnodiales, and the genus Cercospora. The isolate AZ12 (99\% identity with Cercospora sp HQ232415.1 by BLAST) was grouped to the same Cercospora isolate with $84 \%$ BP. In this case, the genus classification was confirmed.

In the seventh clade, comprising representatives from the class Sordariomycetes, the order Xylariales and representatives from the genus Pestalotiopsis, the isolate AZ36 (97\% identity with Pestalotiopsis sp JX436803.1 by BLAST) was grouped to Pestalotiopsis sp isolates (JX684005.1, KC540782.1, JX436803.1, and JX857166.1) with 100\% BP, proving its classification at the genus level.

The eighth clade comprises fungi from the class Sordariomycetes and the order Hypocreales, with representatives from the genus Fusarium. The endophyte AZ2 (99\% identity with Gibberella moniliformis AB649145.1, teleomorphic phase of Fusarium sp, by BLAST) was grouped to the G. moniliformis isolate, the most similar by BLAST, and Fusarium sp isolates (EF680752.1, EF680755.1, and HQ631016.1).

The last clade of phylogenetic analysis of E. azurea endophytes is formed by representatives of the class Sordariomycetes, the order Diaporthales, and the genus Diaporthe, where the isolate AZ5 (93\% identity with Diaporthe sp KC981086.1 by BLAST) had its sequencing confirmed at the genus level, since it was grouped to Diaporthe sp (KC981086.1) with 70\% BP.

\section{Phylogenetic analysis of $E$. crassipes endophytes based on data from rDNA sequencing}

Phylogenetic analysis divided the endophytes isolated from E. crassipes into five clades, all of which comprised fungi from the phylum Ascomycota (Figure 2).

The first three clades comprises fungi from the class Dothideomycetes and the order Pleosporales. In the first clade, comprising representatives of the genera Bipolaris and Curvularia, the isolate C4 (99\% identity with Bipolaris sp GU017499.1 by BLAST) was grouped to Bipolaris sp (JF767008.1) with 58\% BP. The isolate C8 (99\% identity with Bipolaris papendorfii JQ753972.1 by BLAST) was grouped to Bipolaris sp (HQ631009.1) with 42\% BP, while the isolate C26 (99\% identity with Bipolaris sorokiniana JQ753977.1 by BLAST) was grouped to Bipolaris sp (DQ123600.1) with 92\% BP. In these cases, the genus classification was confirmed. The isolate C6 (99\% identity with Curvularia trifolii KC415610.1 by BLAST) was grouped with $99 \%$ BP to the subclade that grouped fungi from the genera Bipolaris and Curvularia, confirming its classification at the genus level.

The second clade comprises fungal isolates from Phoma spp. The isolate C25 (87\% identity with Phoma sp KC662225.1 by BLAST) had its sequencing confirmed at the genus level, since it was grouped with the Phoma representatives (KC662225.1, KC005682.1, and KC005684.1) with $87 \%$ BP. 
The third clade comprises fungi from the genus Microsphaeropsis, where the isolate C5 (99\% identity with Microsphaeropsis arundinis JX077029.1 by BLAST) was grouped with this same isolate, since it had the greatest similarity by BLAST, with $99 \%$ BP. Therefore, the genus identification, based on rDNA sequencing, was confirmed.

The fourth clade comprises representatives from the class Sordariomycetes, the order Glomerellales, and the genus Plectosphaerella. The isolate C21 (99\% identity with Plectosphaerella cucumerina DQ779781.1 by BLAST) was grouped to Plectosphaerella sp (FJ571479.1) with $77 \%$ BP, confirming its sequencing at the genus level.

The last clade comprises representatives from the class Sordariomycetes, the order Glomerellales, and the genus Cercospora, where the isolate C9 (99\% identity with Cercospora kikuchii AY633838.1 by BLAST) was grouped to Cercospora sp (JQ754040.1) with 35\% BP; its genus identification based on rDNA sequencing was thereby confirmed.

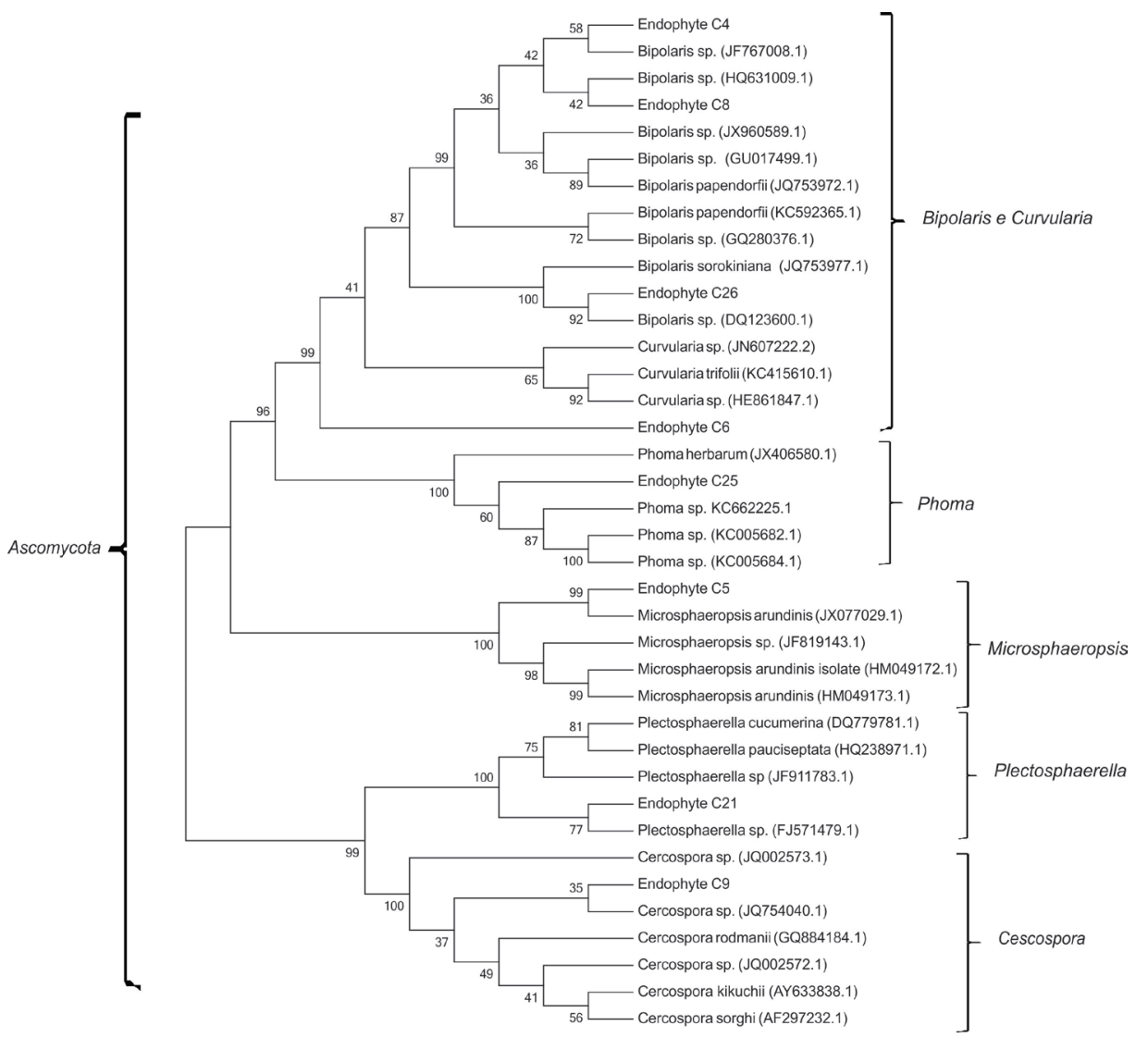

Figure 2. Phylogenetic tree constructed with endophytic sequences from Eichhornia crassipes and sequences from GenBank (indicated by database code), using the neighbor-joining method and the p-distance matrix for nucleotides, with the pairwise gap deletion option. The numbers above and beneath each knot indicate the frequency (\%) of each branch in bootstrap analyses of 10,000 repetitions. All clades comprise fungi from the phylum Ascomycota. Clades I to III comprise fungi from the class Dothideomycetes and the order Pleosporales, with the genera Bipolaris and Curvularia (clade I), Phoma (clade II), and Microsphaeropsis (clade III). Clades IV and V comprise fungi from the class Sordariomycetes and the order Glomerellales, with the genera Plectosphaerella (clade IV) and Cercospora (clade V). 


\section{DISCUSSION}

\section{Isolation and molecular identification of endophytic fungi from E. azurea and E. crassipes}

One of the most interesting features of endophytic fungi is their immense diversity. There are more than one million species of endophyte globally, many of which inhabit individual leaves or other parts of the host plant (Arnold, 2008a). Tropical and subtropical regions host the largest diversity of endophytic species, since these ecosystems are the richest in plant diversity (Banerjee, 2011).

According to Araújo et al. (2010), the surface-disinfection of plant tissues is the most important step in the isolation process and aims to eliminate the external (epiphytic) community of microorganisms, maintaining a viable internal (endophytic) community of plant samples. The process of isolation of endophytes from surface-disinfected plant samples, with cultivation on an appropriate culture medium, has been employed by other authors (Araújo et al., 2010; Gazis and Chaverri, 2010; Sakayaroj et al., 2010; García et al., 2012; Orlandelli et al., 2012; Rhoden et al., 2012). The high isolation frequencies of endophytic fungi from $E$. azurea $(87.86 \%)$ and E. crassipes $(88.85 \%)$ are similar to the results reported by Gazis and Chaverri (2010), where $90 \%$ of leaf samples from tropical rubber trees were colonized by endophytes. The present results for aquatic macrophytes are higher than those obtained by Li et al. (2010), were the colonization frequencies of endophytic fungi in aquatic/riparian Chinese plants varied between 18 and $63 \%$.

The fungal endophytes isolated from E. azurea and E. crassipes were molecularly identified as belonging to 10 different genera: Alternaria, Bipolaris, Cercospora, Diaporthe, Gibberella, Microsphaeropsis, Pestalotiopsis, Phoma, Plectosphaerella, and Saccharicola.

García et al. (2012) evaluated the diversity and colonization of foliar endophytic fungi from the medicinal plant Sapindus saponaria by the sequencing of the ITS region of rDNA and, when possible, by their microscopic features. These authors identified 13 isolates at the genus or species level, and the genera Cochliobolus, Alternaria, Curvularia, and Phomopsis were the most prevalent. Similarly, Rhoden et al. (2012) investigated the diversity of fungal endophytes in leaves from the tropical medicinal tree Trichilia elegans, observing that from 97 isolates selected for study, 13 were identified as belonging to the genera Phomopsis, Diaporthe, Dothideomycete, and Cordyceps, with predominance of the genus Phomopsis.

The genera Alternaria and Bipolaris were the most prevalent in E. azurea and E. crassipes, respectively. The genus Alternaria comprises cosmopolitan fungi that can occur as pathogens, infecting and causing harm to several plants of economic importance, such as tangerines (Citrus reticulata), apples (Malus domestica), pears (Pyrus pyrifolia), tomatoes (Lycopersicon esculentum), and potatoes (Solanum tuberosum) (Peever et al., 2004). In addition, Alternaria isolates have been found as endophytes in other tropical host plants (Sakayaroj et al., 2010; García et al., 2012; Orlandelli et al., 2012).

Species in the genus Bipolaris can also be plant pathogens, causing leaf blotch on sorghum (Ünal et al., 2011). The species of this genus are the predominant endophytes in the leaves of the medicinal plant Piper hispidum (Orlandelli et al., 2012), and are also found in other host plants (Kharwar et al., 2008; Sakayaroj et al., 2010). Therefore, a fungus that as- 
ymptomatically occupies a plant tissue, such as an endophyte, may be a weak pathogen or a virulent strain that was detected during its latency period, or just an inhabitant of an ecological niche waiting for the ideal conditions to propagate (Schulz and Boyle, 2005).

\section{Phylogenetic analyses of endophytic fungi isolated from $E$. azurea and $E$. crassipes}

According to Rhoden et al. (2013), the database GenBank is sufficiently robust to be applicable to studies where molecular identification of the endophytic community is required. The rDNA sequences obtained by sequencing methodologies, where ITS1-5.8S-ITS2 regions of rDNA are amplified, are frequently used for the analysis of fungal diversity at the species level, owing to the rapid rate of evolution in ITS, the ease of recovery of ITS data, and the abundance of these data in GenBank (Arnold et al., 2007; Arnold, 2008b). In addition to rDNA sequencing, phylogenetic analyses were employed to confirm the results obtained (Higgins et al., 2007).

In the present study, phylogenetic analyses confirmed, with 99 to $100 \% \mathrm{BP}$, the sequencing of the endophytic isolates AZ2, AZ5, AZ7, AZ11, AZ12, AZ16, AZ19, AZ20, AZ36, AZ38, C4, C6, C8, C9, C21, C25, and C26 at the genus level; whereas they confirmed with $99 \%$ BP the molecular identification of endophytes AZ13, AZ37, and C5 at the species level.

Orlandelli et al. (2012) also used BLAST to compare rDNA sequences of fungal endophytes from P. hispidum with those deposited in the GenBank database. Phylogenetic analysis confirmed, with $90 \% \mathrm{BP}$, the molecular identification of most of the isolates at the genus level. For some isolates, the identification was confirmed, with $99 \%$ BP, at the species level. However, one isolate was only identified at the order level. The phylogenetic tree constructed with P. hispidum endophytes was divided into five clades: one comprising the phylum Ascomycota and the class Sordariomycetes; three comprising the phylum Ascomycota and different orders from the class Dothideomycetes; and one clade comprising the phylum Basidiomycota and the class Agaricomycetes.

In this study, it was possible to indicate a high foliar colonization by fungal endophytes in the leaves of E. azurea and E. crassipes. By sequencing of ITS1-5.8S-ITS2 of rDNA and phylogenetic analyses, 21 endophytic fungi were identified as belonging to 10 different genera, where two of these isolates were identified at the species level (Microsphaeropsis arundinis). The genera Bipolaris, Cercospora, Microsphaeropsis, and Phoma were found in both species of aquatic macrophytes. The other six genera were host-specific, being isolated from only one host plant: Alternaria, Diaporthe, Gibberella, Pestalotiopsis, Saccharicola (E. azurea), and Plectosphaerella (E. crassipes). Therefore, these results demonstrate a small difference in the endophytic diversity of the two Eichhornia species analyzed.

\section{ACKNOWLEDGMENTS}

The authors thank Laboratório de Biologia Molecular e Estrutural - COMCAP/UEM, for the sequencing of ITS1-5.8S-ITS2 regions; Prof. Dr. Sidinei Magela Thomaz, for help in collection and identification of aquatic macrophytes; and Coordenação de Aperfeiçoamento de Pessoal de Nível Superior (CAPES) for the master's scholarship. The authors received financial support from CNPq (Project \#480726/2011-6). 


\section{REFERENCES}

Aboul-Enein AM, Al-Abd AM, Shalaby E, Abul-Ela F, et al. (2011). Eichhornia crassipes (Mart) solms: from water parasite to potential medicinal remedy. Plant Signal. Behav. 6: 834-836.

Araújo WL, Lacava PT, Marcon J, Lima AOS, et al. (2010). Guia Prático: Isolamento e Caracterização de Microrganismos Endofíticos. 2nd edn. CALQ, Piracicaba.

Arnold AE (2008a). Hidden within our botanical richness, a treasure trove of fungal endophytes. Plant Press 32: 13-15.

Arnold AE (2008b). Endophytic Fungi: Hidden Components of Tropical Community Ecology. In: Tropical Forest Community Ecology (Carson W and Schnitzer S, eds.). Blackwell Scientific, Inc., Malden, 254-271.

Arnold AE, Henk DA, Eells RL, Lutzoni F, et al. (2007). Diversity and phylogenetic affinities of foliar fungal endophytes in loblolly pine inferred by culturing and environmental PCR. Mycologia 99: 185-206.

Azevedo JL, Barros NM and Serafini LA (2002). Biotecnologia: Avanços na Agricultura e na Agroindústria. 1st edn. EDUCS, Caxias do Sul.

Azevedo Netto JM (1988). Novos conceitos sobre eutrofização. Revista DAE 48: 22-28.

Banerjee D (2011). Endophytic fungal diversity in tropical and subtropical plants. Res. J. Microbiol. 6: 54-62.

Casabianca MC (1985). Eichhornia crassipes: Production in repeated harvest systems on waste water in the Languedoc Region (France). Biomass 7: 135-160.

Chigbo FE, Smith RW and Shore FL (1982). Uptake of arsenic, cadmium, lead and mercury from polluted waters by the water hyacinth Eichornia crassipes. Environ. Pollut. 27: 31-36.

Cilliers CJ (1998). Biological control of water hyacinth, Eichhornia crassipes (Pontederiaceae), in South Africa. Agric. Ecosystems Environ. 37: 207-217.

da Cunha-Santino MB, Bianchini I and Okawa MH (2010). O destino dos detritos de Eichhornia azurea (Sw.) Kunth. em um reservatório tropical. Acta Limnol. Bras. 22: 109-121.

Esteves FA (1998). Fundamentos de Limnologia. 2nd edn. Interciência/Finep, Rio de Janeiro.

García A, Rhoden SA, Rubin Filho CJ, Nakamura CV, et al. (2012). Diversity of foliar endophytic fungi from the medicinal plant Sapindus saponaria L. and their localization by scanning electron microscopy. Biol. Res. 45: 139-148.

Gazis R and Chaverri P (2010). Diversity of fungal endophytes in leaves and stems of wild rubber trees (Hevea brasiliensis) in Peru. Fungal Ecol. 3: 240-254.

Higgins KL, Arnold AE, Miadlikowska J, Sarvate SD, et al. (2007). Phylogenetic relationships, host affinity, and geographic structure of boreal and arctic endophytes from three major plant lineages. Mol. Phylogenet. Evol. 42: 543-555.

Kharwar RN, Strobel GA and Ezra D (2008). The endophytic fungal complex of Catharanthus roseus (L.). G. Don. Curr. Sci. 95: 228-233.

Li HY, Zhao CA, Liu CJ and Xu XF (2010). Endophytic fungi diversity of aquatic/riparian plants and their antifungal activity in vitro. J. Microbiol. 48: 1-6.

Lima AF, Lansac-Tôha FA, Velho LFM, Bini LM, et al. (2003). Composition and abundance of Cladocera (Crustacea) assemblages associated with Eichhornia azurea (Swartz) Kunth stands in the Upper Paraná River floodplain. Acta Sci. Biol. Sci. 25: 41-48.

Linnakoski R, Puhakka-Tarvainen H and Pappinen A (2012). Endophytic fungi isolated from Khaya anthotheca in Ghana. Fungal Ecol. 5: 298-308.

Marques DM (1999). Terras Úmidas Construídas de Fluxo Subsuperficial. In: Tratamento de Esgotos Sanitários por Processo Anaeróbio e Disposição Controlada no Solo (Campos JR, ed.). ABES, Rio de Janeiro, 409-435.

Mullis K and Faloona F (1987). Specific synthesis of DNA in vitro via a polymerase catalysed chain reaction. Methods Enzymol. 55: 335-350.

Orlandelli RC, Alberto RN, Rubin Filho CJ and Pamphile JA (2012). Diversity of endophytic fungal community associated with Piper hispidum (Piperaceae) leaves. Genet. Mol. Res. 11: 1575-1585.

Pamphile JA and Azevedo JL (2002). Molecular characterization of endophytic strains of Fusarium verticillioides (Fusarium moniliforme) from maize (Zea mays L.). World J. Microbiol. Biotechnol. 18: 391-396.

Peever TL, Su G, Carpenter-Boggs L and Timmer LW (2004). Molecular systematics of citrus-associated Alternaria species. Mycologia 96: 119-134.

Peixoto Neto PAS, Azevedo JL and Araújo WL (2002). Microrganismos endofíticos: interação com as plantas e potencial biotecnológico. Biotecnol. Cienc. Desenvolv. 29: 62-76.

Rhoden SA, Garcia A, Rubin Filho CJ, Azevedo JL, et al. (2012). Phylogenetic diversity of endophytic leaf fungus isolates from the medicinal tree Trichilia elegans (Meliaceae). Genet. Mol. Res. 11: 2513-2522.

Rhoden SA, Garcia A, Azevedo JL and Pamphile JA (2013). In silico analysis of diverse endophytic fungi by using ITS15,8S-ITS2 sequences with isolates from various plant families in Brazil. Genet. Mol. Res.12: 935-950.

Genetics and Molecular Research 14 (2): 4920-4931 (2015) 
Saitou N and Nei M (1987). The neighbor-joining method: a new method for reconstructing phylogenetic trees. Mol. Biol. Evol. 4: 406-425.

Sakayaroj J, Preedanon S, Supaphon O, Jones EBG, et al. (2010). Phylogenetic diversity of endophyte assemblages associated with the tropical seagrass Enhalus acoroides in Thailand. Fungal Divers. 42: 27-45.

Schulz B and Boyle C (2005). The endophytic continuum. Mycol. Res. 109: 661-686.

Souza AQL, Souza ADL, Astolfi Filho S, Pinheiro MLB, et al. (2004). Atividade antimicrobiana de fungos endofíticos isolados de plantas tóxicas da Amazônia: Palicourea longiflora (Aubl) Rich e Strychnos cogens Bentham. Acta Amaz. 34:185-195.

Souza-Franco GM, Andrian IF and Franco RM (2009). Comunidade de insetos aquáticos associados à Eichhornia azurea (Schwartz) Kunth, em uma lagoa de várzea na planície de inundação do alto Rio Paraná, Mato Grosso do Sul, Ms, Brasil. Biológico 71: 83-91.

Tamura K, Peterson D, Peterson N, Stecher G, et al. (2011). MEGA5: molecular evolutionary genetics analysis using maximum likelihood, evolutionary distance, and maximum parsimony methods. Mol. Biol. Evol. 28: 2731-2739.

Thomaz SM and Bini LM (2003). Ecologia e Manejo de Macrófitas Aquáticas. 5th edn. EDUEM, Maringá.

Thompson JD, Higgins DG and Gibson TJ (1994). CLUSTAL W: improving the sensitivity of progressive multiple sequence alignment through sequence weighting, positions-specific gap penalties and weight matrix choice. Nucleic Acids Res. 22: 4673-4680.

Ünal F, Turgay EB and Yildirim A (2011). First report of leaf blotch on sorghum caused by Bipolaris spicifera in Turkey. Plant Disease 95: 495-498.

White TJ, Bruns TD, Lee S, Taylor JW, et al. (1990). Amplification and Direct Sequencing of Fungal Ribosomal RNA Genes for Phylogenetics. In: PCR Protocols: a Guide to Methods and Applications (Innis MA, Gelfand DH, Sninsky JJ and White TJ, eds.). Academic Press, San Diego, 315-322. 